\title{
Identification of Different Copper Green Pigments in Renaissance Paintings by Cluster-TOF-SIMS Imaging Analysis
}

\author{
Pascale Richardin, ${ }^{1}$ Vincent Mazel, ${ }^{1,2}$ Philippe Walter, ${ }^{1}$ Olivier Laprévote, ${ }^{3,4}$ \\ Alain Brunelle ${ }^{4}$ \\ ${ }^{1}$ Laboratoire du Centre de Recherche et de Restauration des Musées de France (LC2RMF), CNRS - UMR 171, \\ Palais du Louvre, Porte des Lions, 14 quai François Mitterrand, 75001 Paris, France \\ ${ }^{2}$ Laboratoire Matériaux et Santé, EA 401, Faculté de Pharmacie de Châtenay-Malabry, Université de Paris-Sud, \\ Châtenay-Malabry, France \\ ${ }^{3}$ Chimie Toxicologie Analytique et Cellulaire, EA4463, Faculté des Sciences Pharmaceutiques et Biologiques, \\ Université Paris Descartes, Paris, France \\ ${ }^{4}$ Centre de Recherche de Gif, Institut de Chimie des Substances Naturelles, CNRS, Gif-sur-Yvette, France
}

\begin{abstract}
Time-of-flight secondary ion mass spectrometry (TOF-SIMS) imaging using cluster primary ion beams is used for the identification of a green painting layer on the scene The Angels Concert from the Issenheim Altarpiece (painted in 1516) from a German Renaissance painter, Matthias Grünewald. Copper carboxylate clusters inside a basic copper chloride (atacamite) layer have been identified and located in the copper green layer. The mechanisms of transformation of atacamite into copper carboxylates may be initiated by an aging of the paint layers. The combination of the high mass resolution of the technique together with a micrometer spatial resolution and the possibility to simultaneously identify both minerals and organics, has proven to be the method of choice for the study of the stratigraphy of a paint cross-section.
\end{abstract}

Key words: Copper green pigments, Copper carboxylates, Atacamite, Renaissance altarpieces, Cluster- TOF-SIMS, Matthias Grünewald, Mass spectrometry imaging, Painting cross-section

\section{Introduction and Research Aims}

$\mathrm{T}$ he Issenheim Altarpiece is a monumental polyptych, now shown at the Unterlinden Museum (Colmar, France). This masterpiece from Matthias Grünewald (c. 1470-August 31, 1528), a major painter of the German Renaissance, was completed in 1516 for the monastery of the order of St. Anthony, located near Colmar at Issenheim, and consists of 10 different painted panels, full of colors, which depict scenes from the life of Christ and of St. Anthony.

Correspondence to: Pascale Richardin; e-mail: pascale.richardin@culture. gouv.fr
In 2006, during an extensive analysis of the painting technique used by Grünewald for the making of this altarpiece, and in order to establish a complete preservation state, a series of non-destructive in situ analytical methods were performed, like X-ray fluorescence (XRF), Raman spectroscopy, together with photographic and radiographic examinations [1]. In addition to the important contribution of these analyses, 22 micro-samples were taken from the painting surface to describe and better understand the complex stratigraphy of the painting layers. All samples were included in a polyester resin and the obtained cross-sections were polished and analyzed by classic imaging techniques, i.e., scanning electron microscopy with energy dispersive X-ray analysis (SEM-EDX), micro-Raman spectroscopy (MRS) and X-ray microdiffraction ( $\mu$-XRD), Xray microfluorescence ( $\mu \mathrm{XRF})$, and $\mathrm{X}$-ray absorption near-edge 
microspectroscopy ( $\mu$-XANES) at the European Synchrotron Radiation Facility (ESRF, Grenoble, France). The obtained results exemplify the very complex technique of Grünewald (nature of the pigments, mixture, and superposition of colors ...) $[2,3]$.

However, some pigments always raise great problems of identification because of their amorphous structure. This is particularly the case for some copper green pigments [4]. If these pigments are only made from mineral compounds, like malachite or verdigris $[5,6]$, they can be relatively easily identified by Raman spectroscopy or X-ray diffraction spectroscopy. However, the problem is not always resolved in the case of organic pigments. Some identifications have been punctually performed by micro-Raman spectroscopy, like copper citrate on a Thai manuscript [7] or copper resinate on a painting of the master Spanish painter, El Greco [8]. Furthermore, the degradation is more frequently observed with organic pigments, and the formation of breakdown products like copper oxalates $[9,10]$ or the 'darkening' of resinates have been mentioned [11, 12].

The present study concerns the identification of a green painting layer used for the scene named The Angels Concert from the Issenheim Altarpiece (Figure 1). A micro-sample, embedded in resin, has been polished to obtain a flat crosssection. This allows the study of the total stratigraphy by

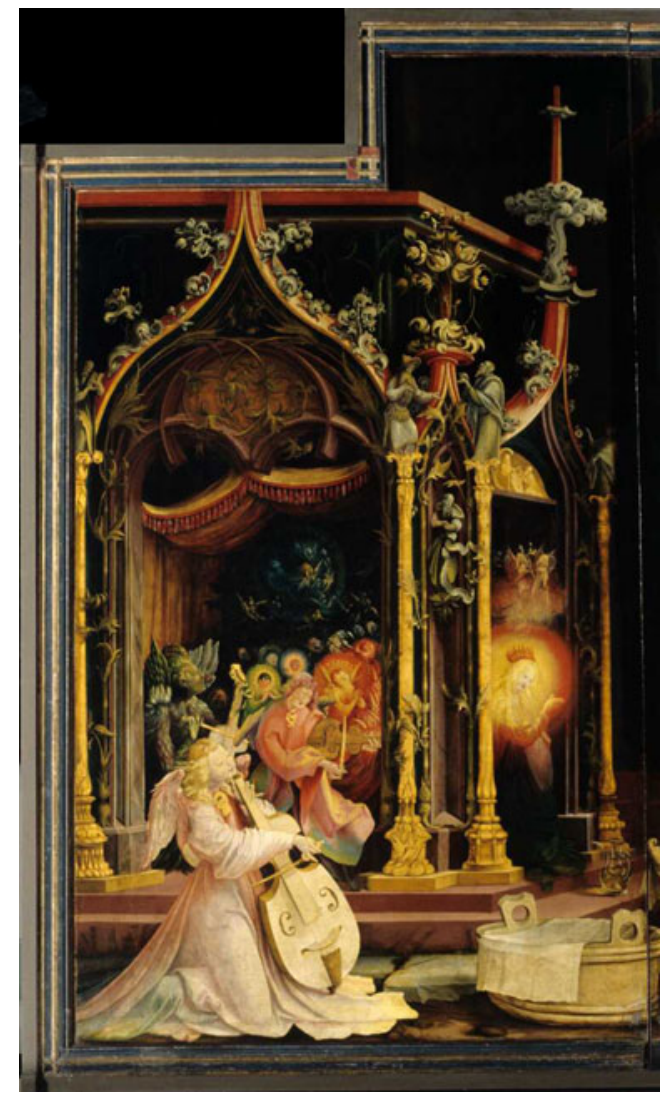

Figure 1. The Issenheim Altarpiece, Matthias Grünewald, 1512-1516. Detail: The Angels concert panel. (CC2RMF, Elsa Lambert) imaging techniques. SEM had shown that the green colored layer is constituted of a mixture of a copper based pigment and lead white. The aim of this research is to use time-offlight secondary ion mass spectrometry (TOF-SIMS) imaging using cluster primary ion beams to identify and locate this copper green pigment, with a spatial resolution and surface sensitivity that is not achievable by conventional techniques, e.g., infrared spectroscopy. Indeed, for nearly 6 years, cluster TOF-SIMS has become a technique of choice to study stratigraphic materials in Cultural Heritage [13], and especially paintings, for the simultaneous location and identification of hybrid materials [14-16].

\section{Experimental}

\section{Sample Preparation}

To be able to characterize and to localize all the compounds inside the sample, cross-sections of paintings are prepared following a previously described procedure [17]. Microsamples are embedded in a polyester resin (Hardclear H59 Sodemi, France) and then cut into $0.5 \mu \mathrm{m}$ sections using a diamond knife (Diatome, Leica Microsystèmes, Nanterre, France). The obtained thin cross-sections are placed on a silicon wafer (Applications Couches Minces ACM, Villiers Saint-Frédéric, France) just before analysis.

\section{Scanning Electron Microscopy with Energy Dispersive X-ray Analysis (SEM-EDX)}

The apparatus used is a Phillips XL30 CP, coupled with an energy dispersive $\mathrm{X}$-ray spectrometer and the accelerating voltage was set to $20 \mathrm{kV}$. Since the sample is embedded in resin and for further analysis, the surface can not be coated with a metallic layer. Indeed, SEM analysis is used to study conductive samples. Organic samples, like painting samples embedded in synthetic resins, are generally coated with gold or carbon on their surface, in the aim to become conductive, thereby avoiding charging effects. In our case, the metallization of the samples would make them unusable for further analysis. Under these conditions, images can only be acquired with backscattered electrons (BSE). To minimize the charging effects, measurements were done in a so-called controlled pressure mode, with a pressure of $0.8 \mathrm{hPa}$.

\section{Time-of-Flight Secondary Ion Mass Spectrometry Imaging}

TOF-SIMS analyses were performed with a TOF-SIMS IV (ION-TOF GmbH, Münster, Germany) reflectron-type TOF mass spectrometer, with a bismuth liquid metal ion gun as the primary ion source. A $25 \mathrm{keV} \mathrm{Bi}_{3}{ }^{+}$ion beam was selected with an incidence angle of $45^{\circ}$ in the so-called 'high current bunched mode' [18]. This ion source operating mode ensures both a 1-2 $\mu \mathrm{m}$ primary ion beam focus and a high mass resolution $\left(\mathrm{M} / \Delta \mathrm{M}=6.10^{3}\right.$, FWHM at $\left.\mathrm{m} / \mathrm{z} 500\right)$. Each 
image was acquired over a surface of $200 \mu \mathrm{m} \times 200 \mu \mathrm{m}$ and $256 \times 256$ pixels, resulting in a lateral resolution of $\sim 0.8 \mu \mathrm{m}$. The primary ion dose density (=fluence) was $4.8 \times 10^{11}$ ions per $\mathrm{cm}^{2}$ only, well below the so-called 'static SIMS limit' [19], in order to preserve the molecular information. Secondary ions are extracted with a $2 \mathrm{kV}$ voltage and are post-accelerated to a $10 \mathrm{keV}$ kinetic energy just before impacting the detector surface, in order to ensure good detection efficiency. A low energy electron flood gun was activated between two successive pulses of the primary ion beam to neutralize any residual charge on the surface of the samples.

Because of the very low initial kinetic energy distribution of the secondary ions, the relationship between the time-offlight and the square root of $\mathrm{m} / \mathrm{z}$ is always linear over the whole mass range. The mass calibration was always internal and signals used for initial calibration were those of $\mathrm{H}^{+}, \mathrm{H}_{2}{ }^{+}$, $\mathrm{H}_{3}{ }^{+}, \mathrm{C}^{+}, \mathrm{CH}^{+}, \mathrm{CH}_{2}{ }^{+}, \mathrm{CH}_{3}{ }^{+}$, and $\mathrm{C}_{2} \mathrm{H}_{5}{ }^{+}$for the positive-ion mode and the signals of $\mathrm{C}^{-}, \mathrm{CH}^{-}, \mathrm{C}_{2}^{-}$, and $\mathrm{C}_{2} \mathrm{H}^{-}$for the negative-ion mode.

The data acquisition and processing software were IonSpec and IonImage, respectively (TOF-SIMS 4.1; IONTOF GmbH, Münster, Germany). The name of the compounds or the $\mathrm{m} / \mathrm{z}$ value of the peak centroid, the maximal number of counts in a pixel (mc), and the total number of counts (tc) are written below each image. The color scales correspond to the $[0, \mathrm{mc}]$ intervals. Regions of interest (ROIs) corresponding to different image areas were drawn with the IonImage software. The associated mass spectra were further extracted in order to reveal different local chemical compositions.

\section{Results and Discussion}

Light microscopy and SEM/EDX analysis give a first approximation of the composition of the MGN8 paint cross-section (Figure 2). Different layers can be clearly distinguished and their elemental compositions are given. From top to bottom, the first layer, which consists of an organic varnish, lies on top of a very broad and green paint layer. It is composed of mixtures of a 'copper green' type pigment and lead white with different relative concentrations. Then, a very thin brown-black layer, mostly made of organic materials is followed by a red layer, which is a mixture of lead white, iron oxide, and clays (aluminosilicate type). A thin lead white layer represents finally the ground layer.

The first step in the investigation was to determine the spatial distribution of copper from positive-ion images obtained by cluster-TOF-SIMS. The paint cross-section was oriented along the diagonal of a square of $200 \mu \mathrm{m}$ a side (Figure 3a). Copper was located by the sum of all the images of singly charged $\mathrm{Cu}_{\mathrm{n}}{ }^{+}(n=1-3)$ cations $\left(\mathrm{Cu}_{1}{ }^{+}\right.$: sum of images of ions at $\mathrm{m} / \mathrm{z} 62.93$ and $64.93, \mathrm{Cu}_{2}{ }^{+}$: sum of images of ions at $m / z 125.88,127.88$, and 129.88, and $\mathrm{Cu}_{3}{ }^{+}$: sum of images of ions at $m / z 188.81,190.81,192.88$, and
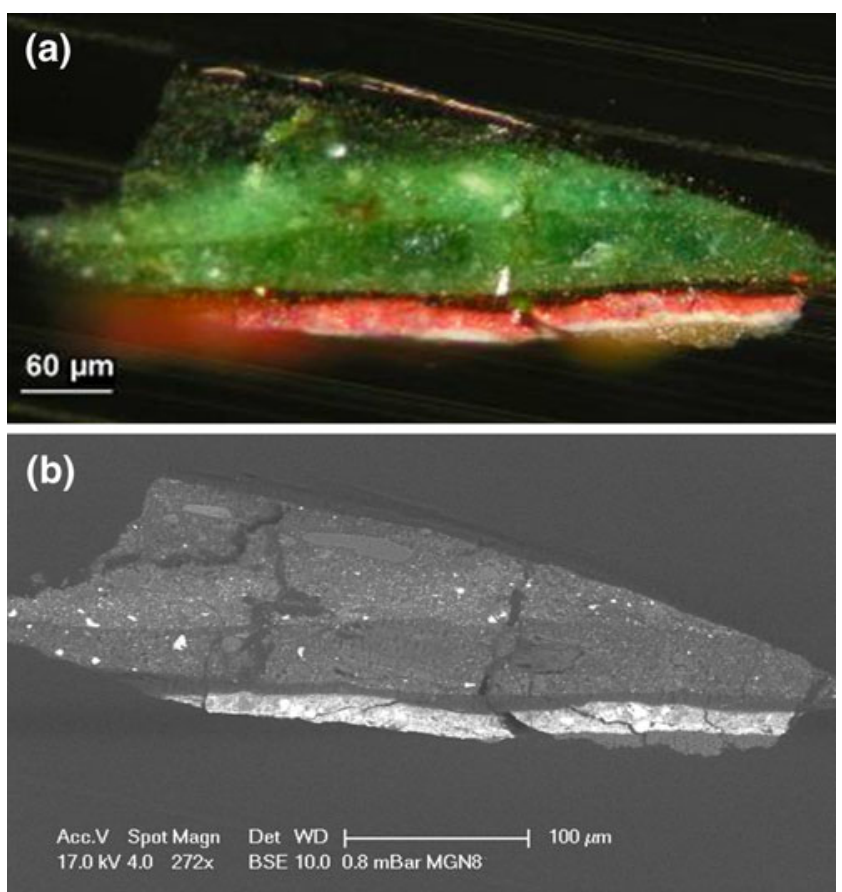

Figure 2. Painting cross-section MGN8 (a) microscopic and (b) BSE image

194.88) with the respective contributions of the two isotopes ${ }^{63} \mathrm{Cu}$ and ${ }^{65} \mathrm{Cu}$ (Figure $3 \mathrm{~b}$ to e). It can be verified that copper is located in the green layers of the cross-section.

Lipids were mapped in the negative-ion mode, in the $\mathrm{m} / \mathrm{z}$ 200-350 range, by selecting a series of fatty acids (FA) carboxylate ion peaks $\left(\mathrm{R}-\mathrm{COO}^{-}\right)$to draw their respective ion images [20]. In oil paintings, these ions can be either free fatty acids or specific fragments of triglycerides. All the individual ion images (Figure $4 \mathrm{a}$ to $\mathrm{h}, \mathrm{m} / \mathrm{z} 227.22,241.23$, $253.24,255.25,267.26,269.28,281.27$, and 283.29) provide the same localization and the sum of all the ion images (Figure 4i) also shows that these lipid ions are accumulated inside the copper rich region (Figure 4j), and are co-localized with the $\left[(\mathrm{FA})_{\mathrm{n}} \mathrm{Cu}_{\mathrm{n}+1}\right]^{+}$(with $n=1$ and 2) ions in ovoid areas of $\sim 5-50 \mu \mathrm{m}$ length (Figure $4 \mathrm{k}$ to $\mathrm{m}$ ).

The TOF-SIMS mass spectrum in the negative-ion mode, automatically selected by the IonImage software from the lipids rich area is shown in Figure 5a. First, this spectrum is dominated by the peaks corresponding to the fatty acids carboxylates ions $[\mathrm{FA}-\mathrm{H}]^{-}$. The major peaks correspond to the fatty acid carboxylates bearing an even number of carbon atoms and C16:0 (P: palmitic acid) gives the most intense peaks of the mass spectrum above $m / z$ 150. Furthermore, between $\mathrm{m} / \mathrm{z} 500$ and 650, a group of peaks centered at $\mathrm{m} / z 573$ with a Gaussian-like shape is detected. Each peak is composed of a copper organic complex, with one atom of copper and two fatty acid carboxylates. These $[2 \mathrm{FA}-2 \mathrm{H}+\mathrm{Cu}]^{-}$ions are all co-localized with those of $[\mathrm{FA}-\mathrm{H}]^{-}$(Figure $4 \mathrm{j}$ and $\mathrm{m}$ ).

Similarly in the positive-ion mode (Figure 5b), two important groups of ions are detected in the same area. 

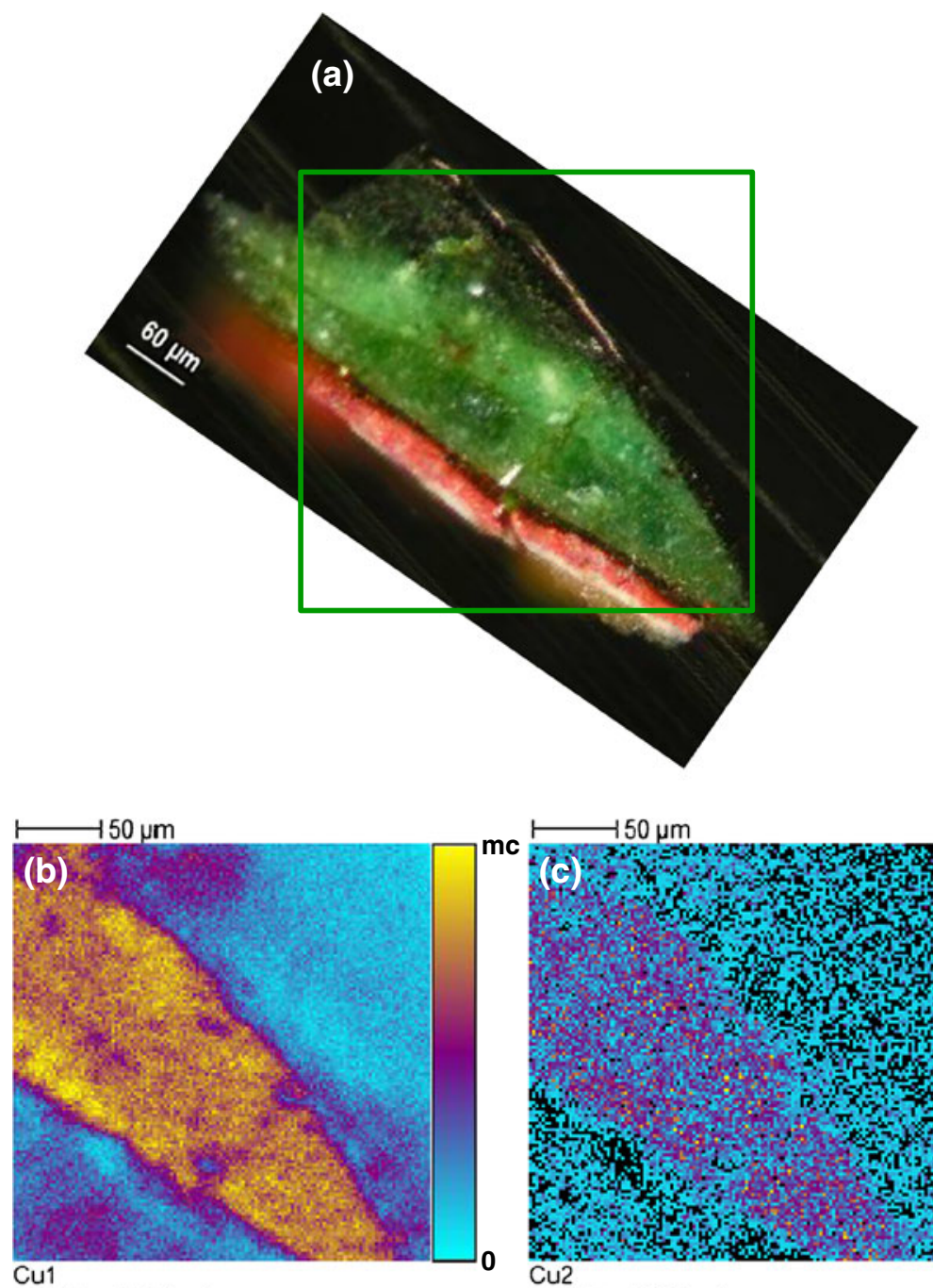

mc: 83 tc: $6.234 \mathrm{e}+5$
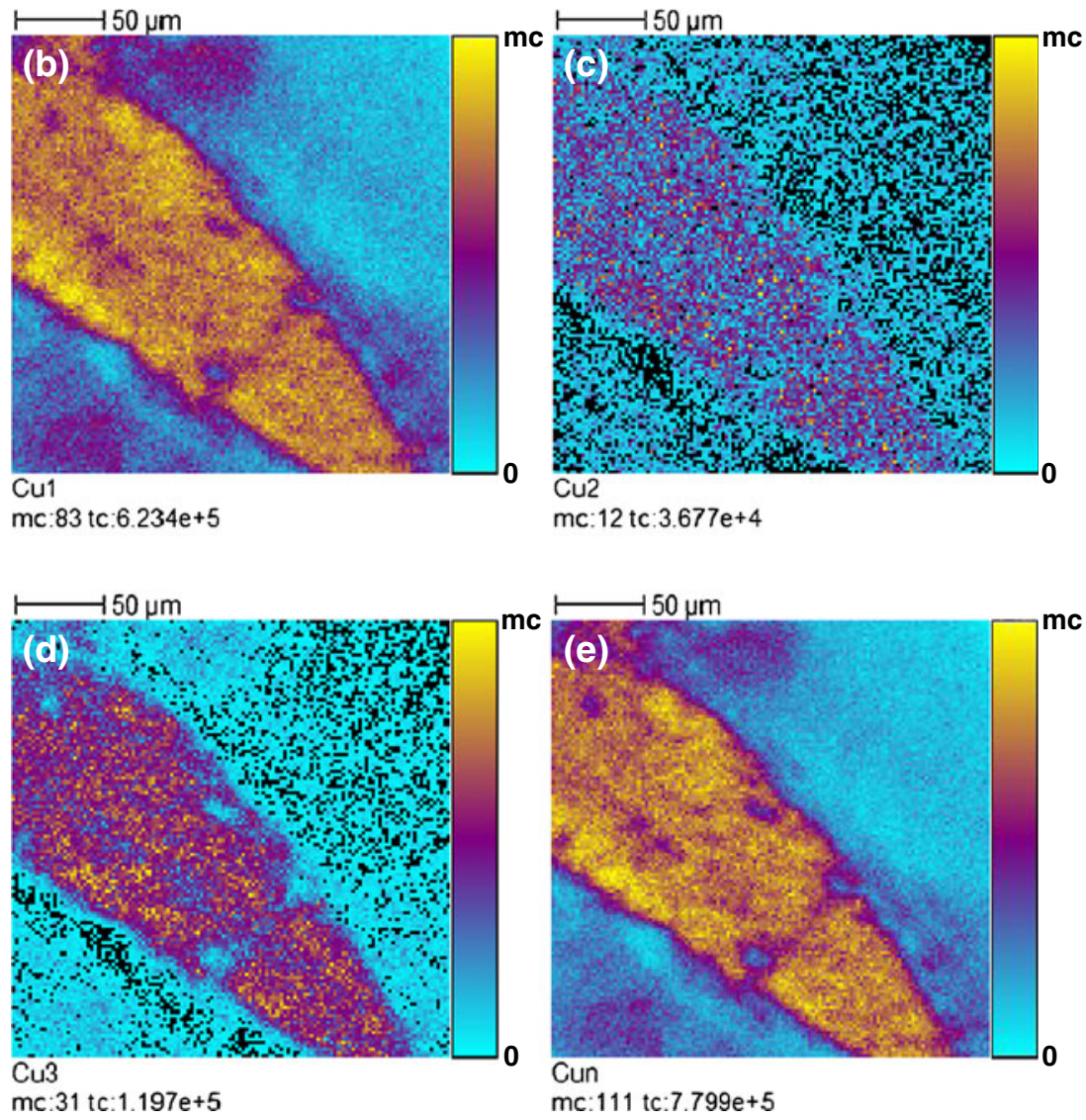

Figure 3. (a) Microscopic image of the paint cross-section at the surface of which the TOF-SIMS images were acquired inside the area of $200 \mu \mathrm{m} \times 200 \mu \mathrm{m}$ delimited by the green square; (b to d) TOF-SIMS ion images recorded in the positive-ion mode: (b) $\mathrm{Cu}_{1}{ }^{+}$(sum of $\mathrm{m} / \mathrm{z} 62.93$ and 64.93 ion images), (c) $\mathrm{Cu}_{2}{ }^{+}$(sum of $\mathrm{m} / \mathrm{z} 125.88,127.88$ and 129.88 ion images), (d) $\mathrm{Cu}_{3}{ }^{+}$(sum of $\mathrm{m} / \mathrm{z}$ 188.81, 190.81, 192.88, and 194.88 ion images), (e) $\mathrm{Cu}_{n}{ }^{+}$(sum of the total $\mathrm{Cu}_{1}{ }^{+}, \mathrm{Cu}_{2}{ }^{+}$and $\mathrm{Cu}_{3}{ }^{+}$ions). Field of view $200 \mu m \times$ $200 \mu \mathrm{m} ; 256 \times 256$ pixels, pixel size $0.78 \mu \mathrm{m}$, fluence $4.8 \times 10^{11}$ ions.cm ${ }^{-2}$. Color scale bars, with amplitude in number of counts, are indicated to the right of each ion image. The amplitude of the color scale corresponds to the maximum number of counts $m c$ and could be read as $[0, m c]$; $t c$ is the total number of counts recorded for the specified $\mathrm{m} / \mathrm{z}$ (sum of counts in all the pixels) 

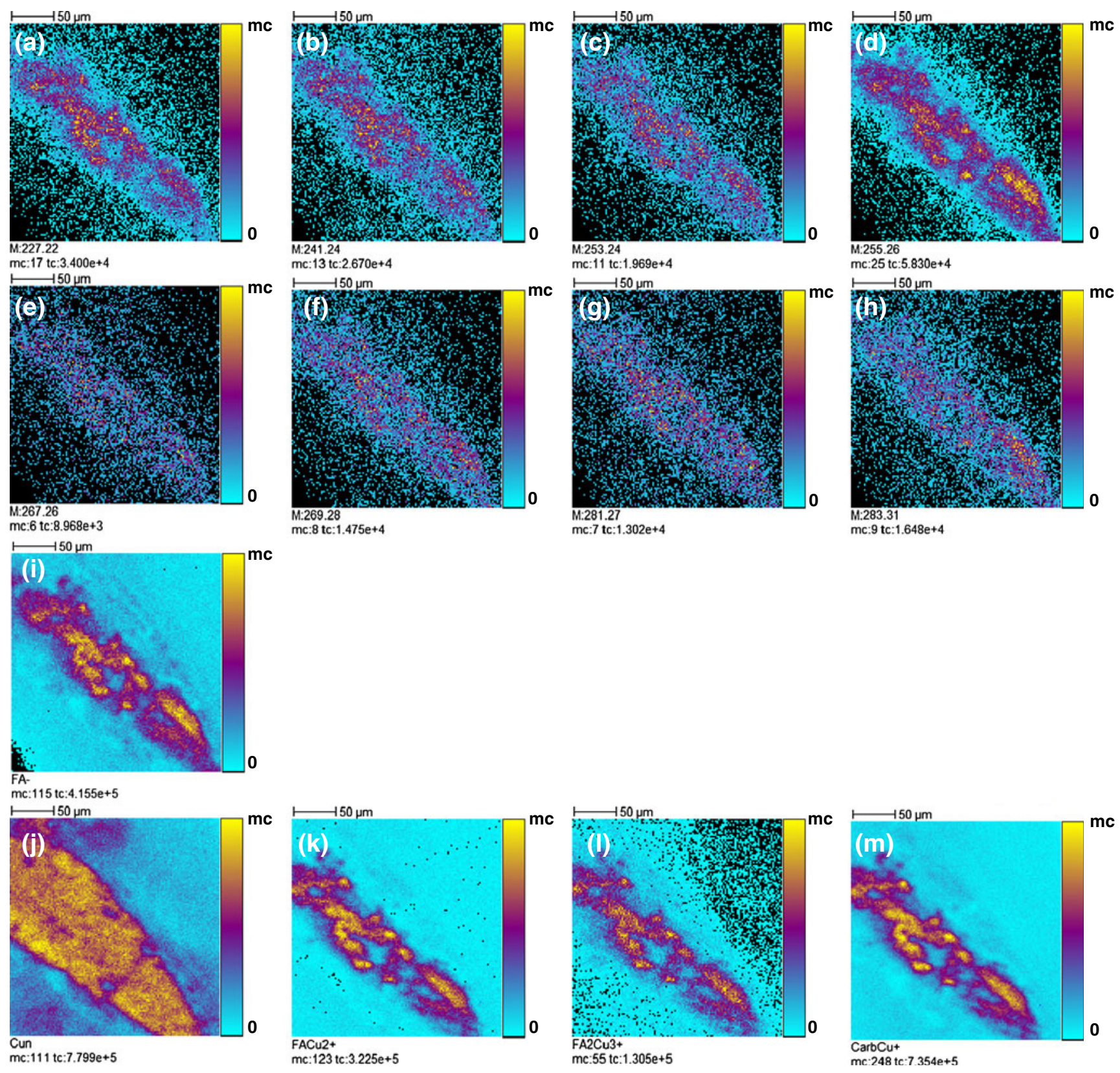

Figure 4. (a to i) TOF-SIMS ion images in the negative ion mode of lipids: (a) $\mathrm{m} / \mathrm{z} 227.22$; (b) $\mathrm{m} / \mathrm{z} 241.24$; (c) $\mathrm{m} / \mathrm{z} 253.24$; (d) $\mathrm{m} / \mathrm{z}$ 255.26; (e) $\mathrm{m} / \mathrm{z}$ 267.26; (f) $\mathrm{m} / \mathrm{z} 269.28$; (g) $\mathrm{m} / \mathrm{z}$ 281.27; (h) $\mathrm{m} / \mathrm{z} 2$ 283.31; and (i) sum of these eight ion images; (j to h) TOF-SIMS ion images in the positive-ion mode of copper carboxylate ions: (j) sum of the $\mathrm{Cu}_{n}{ }^{+}$ions; (k) sum of the $(\mathrm{FA}) \mathrm{Cu}_{2}{ }^{+}$ions; (l) sum of the $(\mathrm{FA})_{2} \mathrm{Cu}_{3}{ }^{+}$ions, and (m) sum of $(\mathrm{FA})_{n} \mathrm{Cu}_{n+1}{ }^{+}$ions; (FA: fatty acid carboxylates). Field of view $200 \mu \mathrm{m} \times 200 \mu \mathrm{m} ; 256 \times 256$ pixels, pixel size $0.78 \mu \mathrm{m}$, fluence $4.8 \times 10^{11}$ ions. $\mathrm{cm}^{-2}$. Color scale bars, with amplitude in number of counts, are indicated to the right of each ion image. The amplitude of the color scale corresponds to the maximum number of counts $m c$ and could be read as $[0$, $m c$ ]; $t c$ is the total number of counts recorded for the specified $m / z$ (sum of counts in all the pixels)

They correspond to compounds with a general formula $(\mathrm{FA})_{\mathrm{n}} \mathrm{Cu}_{\mathrm{n}+1}{ }^{+}(n=1$ and 2$)$. These two mass spectra (in positive-ion and negative-ion modes) are compatible with the presence of copper carboxylates, which would be located inside the green layers of the copper green pigments. Their presence has been confirmed by synchrotron-based Fourier transform infrared micro-spectroscopy ( $\mu$-SR-FTIR) (ESRF, line ID21, data not shown).
In a previous work [21], copper carboxylates have already been identified on an ancient icon by a combination of infrared spectroscopy (FTIR), gas chromatographymass spectrometry (GC-MS), and electron paramagnetic resonance (RPE). These compounds, whose structures are not clearly established, would be produced by the reaction of the oil present in the medium with the copper alloy of the surround during a degradation process. In a same way, 
a
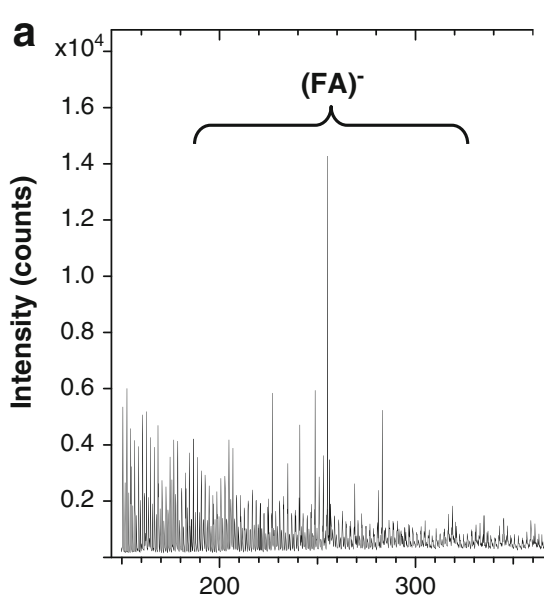

b

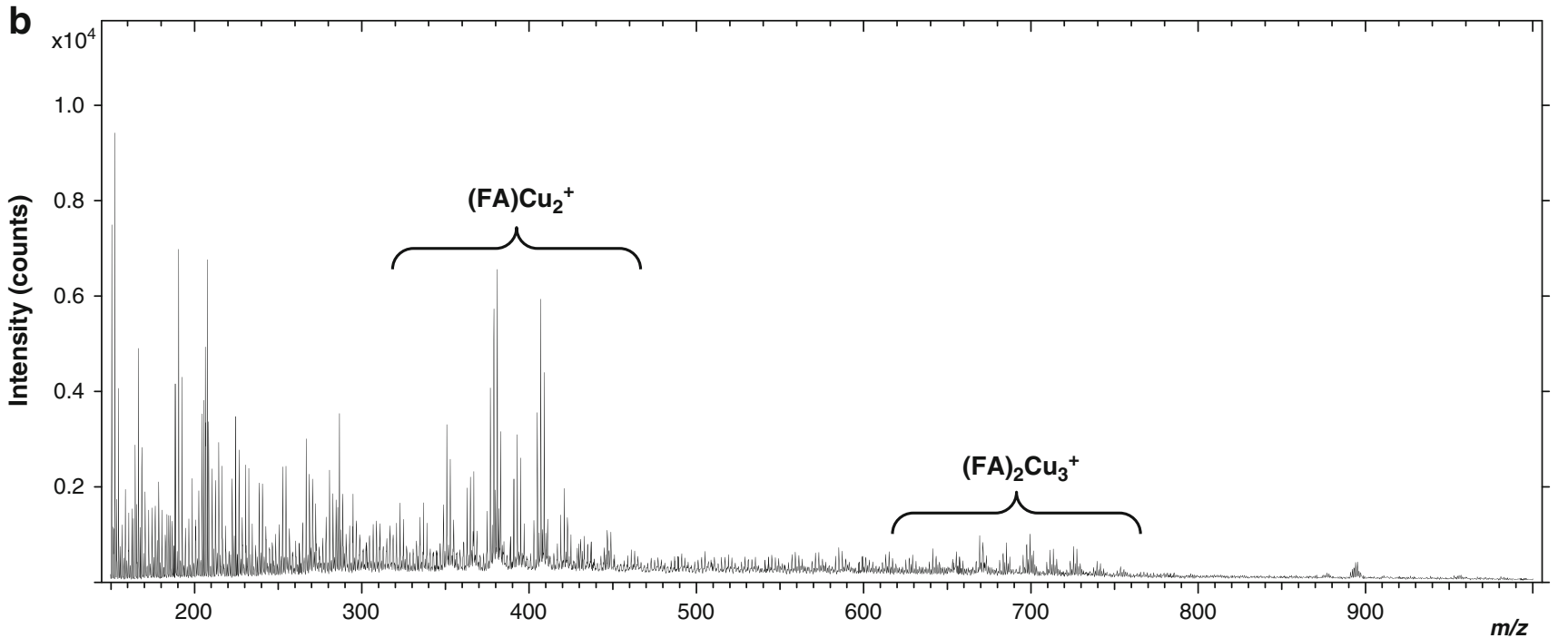

Figure 5. TOF-SIMS mass spectra of copper carboxylates from the area rich in lipids (a) in the negative ion mode and (b) in the positive-ion mode. FA: fatty acid carboxylates, TAG: triacylglycerols, M: myristic acid, P: palmitic acid, and S: stearic acid

others authors [22] proposed, from their using $\mu$-SR-FTIR experiments, that if a green copper-based pigment is present in a painting layer, made either of copper acetates or copper chlorides, further formation of copper carboxylates is always preferred, even if lead-based pigments are also present.

The last step is the identification of the different green layer components. Indeed, in the positive-ion mode, the overlay between the image of $\mathrm{Cu}_{\mathrm{n}}^{+}$copper ions (Figure 4j) and that of the $[2 \mathrm{FA}-\mathrm{H}+2 \mathrm{Cu}]^{+}$copper carboxylates (Figure $4 \mathrm{k}$ and 1 ) shows that the green layer is made of other compounds containing copper, which surround the grains of copper carboxylates. The comparison between the ion images of (1) the copper hydroxide ions $\left[\mathrm{Cu}_{\mathrm{n}}(\mathrm{OH})_{\mathrm{n}-1}\right]^{+}(n=2$ and 3$)$ detected in the positive-ion mode (Figure 6a and b) and (2) the chloride ions $\left({ }^{35} \mathrm{Cl}^{-}\right.$ and ${ }^{37} \mathrm{Cl}^{-}$) and the $\mathrm{CuCl}_{2} \cdot \mathrm{CuOH}^{-}$copper hydroxychloride ions, detected in the negative ion mode (Figure 6c and d), delimits an outer area in the green layer that could correspond to the unknown pigment. This is confirmed by the overlay image between the FA carboxylates ions and the $\mathrm{CuCl}_{2} \cdot \mathrm{CuOH}^{-}$ions shown in Figure $6 \mathrm{f}$.

Then, it can be hypothesized that the green copper pigment could be made of atacamite $\mathrm{Cu}_{2}(\mathrm{OH})_{3} \mathrm{Cl}$, which is a copper 

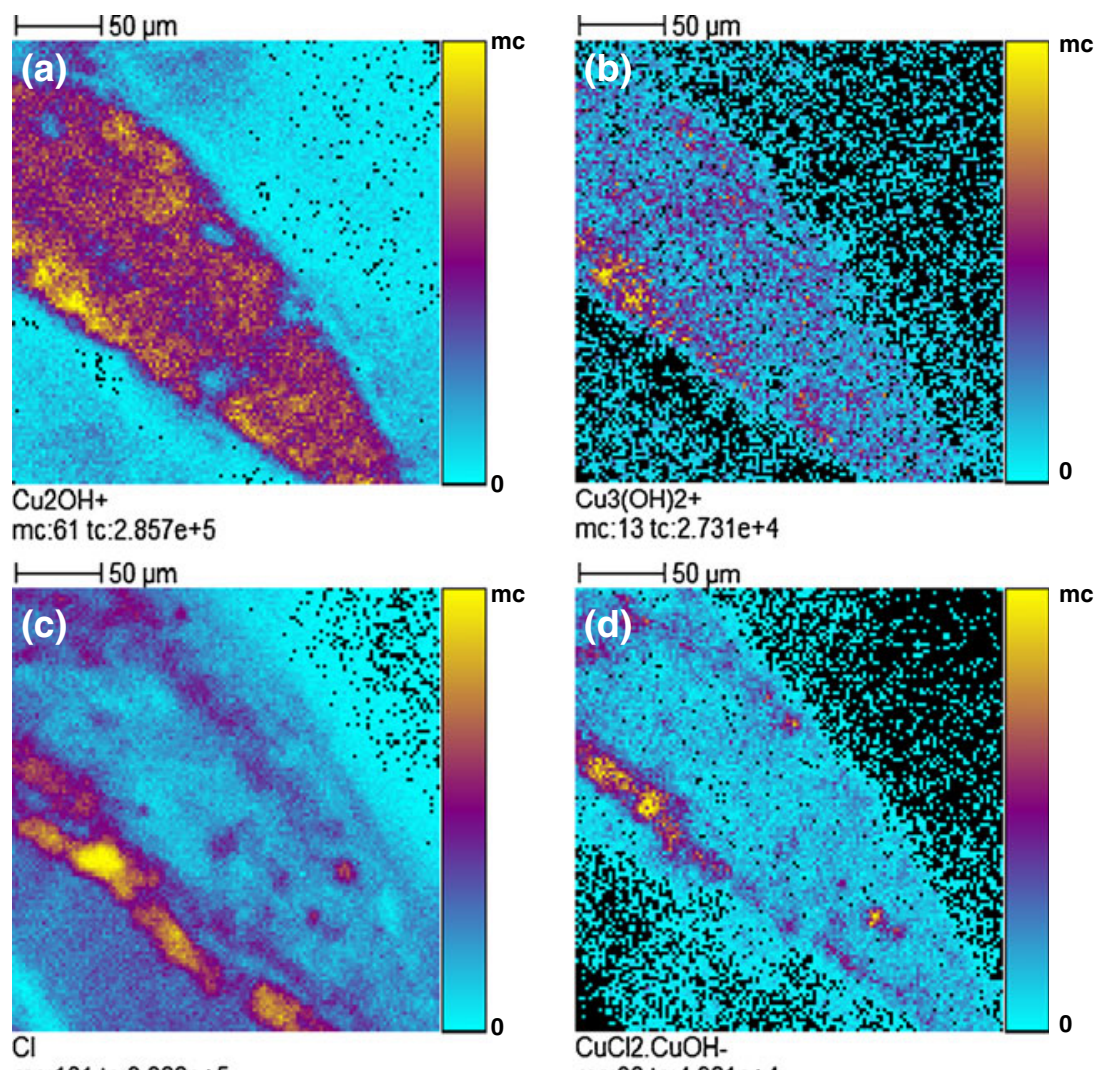

mc:13 tc:2.731e+4
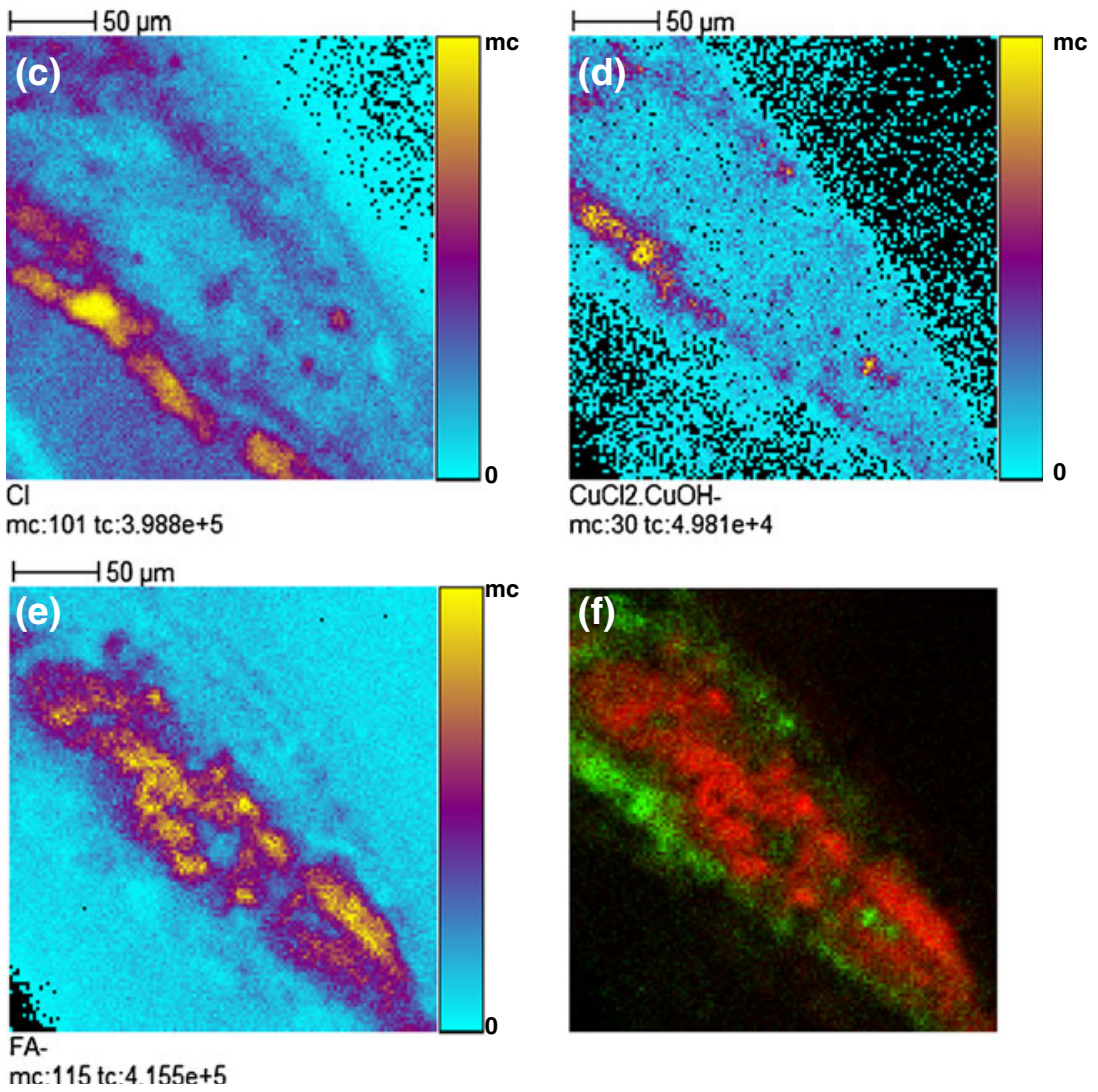

Figure 6. TOF-SIMS ion images in the positive-ion mode: (a) sum of the $\mathrm{Cu}_{2} \mathrm{OH}^{+}$ions; (b) sum of the $\mathrm{Cu}_{3}(\mathrm{OH})_{2}{ }^{+}$ions; $\mathrm{TOF}_{-}$ SIMS ion images in the negative ion mode: (c) $\mathrm{Cl}^{-}$ions; (d) sum of the $\mathrm{CuCl}_{2} . \mathrm{CuOH}^{-}$ions; (e) sum of fatty acid carboxylate ions; and (f) two colors overlay between the sum of the $\mathrm{CuCl}_{2}$ and $\mathrm{CuOH}^{-}$ions (green) and the fatty acid carboxylate ions (red). Field of view $200 \mu \mathrm{m} \times 200 \mu \mathrm{m} ; 256 \times 256$ pixels, pixel size $0.78 \mu \mathrm{m}$, fluence $4.8 \times 10^{11}$ ions.cm ${ }^{-2}$. Color scale bars, with amplitude in number of counts, are indicated to the right of each ion image. The amplitude of the color scale corresponds to the maximum number of counts $m c$ and could be read as $[0, m c]$; $t c$ is the total number of counts recorded for the specified $m / z$ (sum of counts in all the pixels)

trihydroxychloride or "basic-copper chloride," well known to be used as a painting pigment since the 5th $\mathrm{AD}[23]$. The presence in this sample and in this green layer of a mixture of atacamite and paratacamite has also been confirmed by FTIR microscopy and X-ray microdiffraction (ESRF, line ID21 and ID22, data not shown). However, the degradation of the basic copper chloride (atacamite) can also lead to copper carboxylates as it was proposed in a recent study [24].

\section{Conclusion}

TOF-SIMS analysis is currently the only technique that allows the detection and the localization of this type of organo-metallic complexes [copper-fatty acids] at a micrometer scale. So, this research describes the direct identification in one single mass spectrometry imaging experiment of an organic copper green layer, constituted by two different pigments: atacamite and copper carboxylates. Although the 
presence of copper carboxylates may also be due to the degradation of the basic copper chloride (atacamite) in a lipidic system (the binding media), as it was proposed in a recent study [24]. This new example of a TOF-SIMS imaging application in Cultural Heritage studies confirms the high analytical potential of this technique for the study of hybrid materials (organic and inorganic).

\section{Acknowledgments}

The authors thank Éléonore Welcomme for the sample SEM-EDX analysis, and Marine Cotte and Pierre Bleuet for the experiments at the European Synchrotron Radiation Facility (ESRF). Jéril Degrouard and Danielle Jaillard from the Centre Commun de Microscopie Electronique at Orsay, France (CNRS UMR 8080) are thanked for their assistance in ultramicrotomy preparation and Elsa Lambert from the C2RMF for the photographs of the Issenheim altarpiece.

\section{References}

1. Menu, M.; Ezrati, J.-J.; Laval, E.; Pagès, S.; Principaud, A.; Rioux, J.-P.; Walter, P.; Welcomme, E.; Nowik, V. Analyse de la palette des couleurs du retable d'Issenheim par Matthias Grünewald. In La technique picturale de Grünewald et de ses contemporains; Béguerie-De Paepe, P.; Menu, M., Eds; Centre de recherche et de restauration des musées de France: Paris; Musée d'Unterlinden: Colmar, 2007; p. 49.

2. Cotte, M., Welcomme, E., Solé, V.A., Salomé, M., Menu, M., Walter, P., Susini, J.: Synchrotron-Based X-ray Spectromicroscopy Used for the Study of an Atypical Micrometric Pigment in 16th Century Paintings. Anal. Chem. 79(6), 6988-6994 (2007)

3. Welcomme, E., Walter, P., Bleuet, P., Hodeau, J.-L., Dooryhée, E., Martinetto, P., Menu, M.: Classification of lead white pigments using synchrotron radiation micro X-ray diffraction. Appl. Phys. A Mater. Sci. Process 89, 825-832 (2007)

4. Švarcová, S., Hradil, D., Hradilová, J., Kočí, E., Bezdička, P.: MicroAnalytical Evidence of Origin and Degradation of Copper Pigments Found in Bohemian Gothic Murals. Anal. Bioanal. Chem. 395(7), 2037-2050 (2009)

5. de la Roja, J.M., Baonza, V.G., San Andrès, M.: Application of Raman Microscopy to the Characterization of Different Verdigris Variants Obtained Using Recipes from Old Treatises. Spectrochim. Acta 68, 1120-1125 (2007)

6. Castro, K., Sarmiento, A., Martinez-Arkarazo, I., Madariaga, J.M., Fernandez, L.A.: Green Copper Pigments Biodegradation in Cultural Heritage: from Malachite to Moolooite, Thermodynamic Modeling, X-ray fluorescence, and Raman Evidence. Anal. Chem. 80(11), 4103-4110 (2008)

7. Eremin, K., Stenger, J., Huang, J.F., Huang, J.-F., Aspuru-Guzik, A., Betley, T., Vogt, L., Kassal, I., Speakman, S., Khandekar, N.: Examination of Pigments on Thai Manuscripts: The First Identification of Copper Citrate. J. Raman Spectrom. 39(8), 1057-1065 (2008)

8. Daniilia, S., Andrikopoulos, K.S., Sotiropoulou, S., Karapanagiotis, S.: Analytical Study into El Greco's Baptism of Christ: Clues to the Genius of his Palette. Appl. Phys. A Mater. Sci. Process 90, 565-575 (2008)
9. Nevin, A., Loring Melia, J., Osticioli, I., Gautier, G., Colombini, M.P.: The Identification of Copper Oxalates in a 16th Century Cypriot Exterior Wall Painting Using Micro FTIR, Micro Raman Spectroscopy, and Gas Chromatography-Mass Spectrometry. J. Cultural Heritage 9, 154-161 (2008)

10. Castro, K., Sarmiento, A., Martinez-Arkarazo, I., Madariaga, J.M., Fernandez, L.A.: Green Copper Pigments Biodegradation in Cultural Heritage: From Malachite to Moolooite, Thermodynamic Modeling, Xray Fluorescence, and Raman Evidence. Anal. Chem. 80, 4103-4110 (2008)

11. Cartechini, L., Miliani, C., Brunetti, B.G., Sgamellotti, A., Altavilla, C., Ciliberto, E., D’Acapito, F.: X-ray Absorption Investigations of Copper Resinate Blackening in a XV Century Italian Painting. Appl. Phys. A Mater. Sci. Process 92, 243-250 (2008)

12. Altavilla, C., Ciliberto, E.: Copper Resinate: An XPS study of degradation. Appl. Phys. A Mater. Sci. Process 83, 699-703 (2006)

13. Mazel, V.; Richardin, P. TOF-SIMS study of Organic Materials in Cultural Heritage: Identification and Chemical Imaging. In Organic Mass Spectrometry in Art and Archaeology; Colombini M.P.; Modugno F., Eds; Wiley: 2009; p. 433.

14. Sanyova, J., Cersoy, S., Richardin, P., Laprévote, O., Walter, P., Brunelle, A.: Unexpected Materials in a Rembrandt Painting Characterized by High Spatial Resolution Cluster-TOF-SIMS Imaging. Anal. Chem. 83, 753-760 (2011)

15. Keune, K., Boon, J.J.: Imaging Secondary Ion Mass Spectrometry of a Paint Cross Section Taken from an Early Netherlandish Painting by Rogier van der Weyden. Anal. Chem. 76, 1374-1385 (2004)

16. Keune, K., Boon, J.J.: Analytical Imaging Studies Clarifying the Process of the Darkening of Vermilion. Anal. Chem. 77, 4742-4750 (2005)

17. Mazel, V., Richardin, P., Touboul, D., Brunelle, A., Walter, P., Laprévote, O.: Chemical Imaging Techniques for the Analysis of Complex Mixtures: New Application to the Characterization of Ritual Matters on African Wooden Statuettes. Anal. Chim. Acta 570, 34-40 (2006)

18. Brunelle, A., Touboul, D., Laprévote, O.: Biological Tissue Imaging with Time-of-Flight Secondary Ion Mass Spectrometry and Cluster Ion Sources. J. Mass Spectrom. 40, 985-999 (2005)

19. Vickerman, J.C.: TOF-SIMS - an Overview. In: Vickerman, J.C., Briggs, D. (eds.) TOF-SIMS-Surface Analysis by Mass Spectrometry, Surface Spectra and IM Publications, Manchester and Chichester (2001); p. 1

20. Touboul, D., Brunelle, A., Halgand, F., De La Porte, S., Laprévote, O.: Lipid Imaging by Gold Cluster Time-of-Flight Secondary Ion Mass Spectrometry: Application to Duchenne Muscular Dystrophy. J. Lipid Res. 46, 1388-1395 (2005)

21. Gunn, M.; Martin, E. Mécanisme d'altération d'un alliage cuivreux en présence d'un liant huileux. In Art et chimie: La couleur; Goupy, J.; Mohen, J.-P., Eds.; CNRS éditions: Paris, p. 141.

22. Salvado, N., Buti, S., Tobin, M.J., Pantos, E., Prag, J.N.W., Pradell, T.: Advantages of the Use of SR-FT-IR Microspectroscopy: Applications to Cultural Heritage. Anal. Chem. 77(11), 3444-3451 (2005)

23. Salvado, N., Pradell, T., Pantos, E., Papiz, M.Z., Molera, J., Secoe, M., Vendrell-Saz, M.: Identification of Copper-Based Green Pigments in Jaume Huguet's Gothic Altarpieces by Fourier Transform Infrared Microspectroscopy and Synchrotron Radiation X-ray Diffraction. J. Synchrotron Rad. 9, 215-222 (2002)

24. Salvado, N., Butí, S., Nicholson, J., Emerich, H., Labrador, A., Pradelle, T.: Identification of Reaction Compounds in Micrometric Layers from Gothic Paintings Using Combined SR-XRD and SR-FTIR. Talanta 79, 419-428 (2009) 